\title{
Development and Clinical Evaluation of a Rapid Diagnostic Test for Yellow Fever Non-Structural Protein 1
}

\author{
Yeong Hoon Kim ${ }^{1, \dagger}$, Tae-Yun Kim², , Ji-Seon Park', Jin Suk Park², Jihoo Lee², Joungdae Moon², Chom-Kyu Chong², \\ Ivan Neves Junior ${ }^{3}$, Fernando Raphael Ferry 3 , Hye-Jin Ahn', Lokraj Bhatt', Ho-Woo Nam,4,

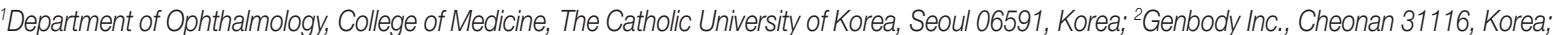 \\ ${ }^{3}$ Gafree and Guinle University Hospital of the Federal University of Rio de Janeiro, Del Castilho, Rio de Janeiro, Brazil; ${ }^{4}$ Department of Parasitology, \\ College of Medicine, The Catholic University of Korea, Seoul 06591, Korea
}

\begin{abstract}
A rapid diagnostic test (RDT) kit was developed to detect non-structural protein 1 (NS1) of yellow fever virus (YFV) using monoclonal antibody. NS1 protein was purified from the cultured YFV and used to immunize mice. Monoclonal antibody to NS1 was selected and conjugated with colloidal gold to produce the YFV NS1 RDT kit. The YFV RDTs were evaluated for sensitivity and specificity using positive and negative samples of monkeys from Brazil and negative human blood samples from Korea. Among monoclonal antibodies, clones 3A11 and 3B7 proved most sensitive, and used for YFV RDT kit. Diagnostic accuracy of YFV RDT was fairly high; Sensitivity was $0.0 \%$ and specificity was $100 \%$ against Dengue viruses type 2 and 3, Zika, Chikungunya and Mayaro viruses. This YFV RDT kit could be employed as a test of choice for point-of-care diagnosis and large scale surveys of YFV infection under clinical or field conditions in endemic areas and on the globe.
\end{abstract}

Key words: Yellow fever, diagnostics, RDT, monoclonal antibody, NS1

\section{INTRODUCTION}

Yellow fever (YF) is an acute febrile disease caused by the yellow fever virus (YFV) belonging to the Flaviviridae family and is endemic in mostly African and South American countries [1]. YF is mainly transmitted by mosquitoes of the genera Aedes sp., Haemagogus sp. and Sabethes sp., so it may occur mainly in areas where these mosquitoes are prevalent [2-4]. Most people are asymptomatic or have a mild infection, but a small proportion of patients develop severe symptoms with a mortality of over 50\% [5]. YF was first reported in 1684 at the Yucatan peninsula of Mexico, and in the 18th to 19th centuries transported to North America and Europe, causing large outbreaks that in some cases decimated populations also in Central and South America [6,7]. Even though an extremely safe and effective vaccine has been available since 1937, YF remains as an important public health problem in these endem-

- Received 27 February 2019, revised 13 June 2019, accepted 16 June 2019.

*Corresponding author (howoo@catholic.ac.kr)

${ }^{\dagger}$ These authors contributed equally to this work

(c) 2019, Korean Society for Parasitology and Tropical Medicine

This is an Open Access article distributed under the terms of the Creative Commons Attribution Non-Commercial License (http://creativecommons.org/licenses/by-nc/4.0) which permits unrestricted non-commercial use, distribution, and reproduction in any medium, provided the original work is properly cited. ic areas [8]. A recent study estimated an annual occurrence of $51,000-380,000$ severe cases of yellow fever and 19,000180,000 deaths due to this disease in Africa alone [9]. A YF outbreak in Angola (2015-2016) caused 4,000 suspicious cases and 600 fatal cases, while in Brazil after December 2016 over 800 patients and over 200 mortalities were identified (May 2017) $[10,11]$.

YFV belongs to the Flaviviridae family. YFV is composed of 3 structural proteins (capsid: $\mathrm{C}$, membrane: $\mathrm{M}$, and envelope: $\mathrm{E}$ ) and 7 non-structural proteins (NS1, NS2a, NS2b, NS3, NS4a, NS4b, and NS5) [7]. The Flavivirus non-structural protein 1 (NS1) is a highly preserved glycoprotein dimer approximately $46-55 \mathrm{kDa}$ in size depending on the degree of glycosylation. The viruses in the Flaviviridae family shows homology, and especially NS1 shows a high homology [12]. NS1 glycosylation is important in effective secretion, toxicity and replication of the virus. NS1 can be detected from the cellular surface or inside infected cells, and are secreted effectively from cells [13]. Intracellular NS1 is central to viral replication, secreted and recently bound NS1 is important in inducing immune reactions [3]. NS1 from patients' serum infected with WNV and DENV in the Flaviviridae family are used as initial markers. However, in contrast to other Flaviviridae, not much is known about the 
expression and secretion of YFV.

Laboratory diagnosis can provide a rapid and accurate differential identification of the pathogen and may help in the appropriate management of YF. YFV infection can be detected by several methods such as viral isolation and RNA detection from the blood, and antibody detection from the serum $[14,15]$. Several methods such as haemaglutination inhibition test, complement fixation test, plaque reduction neutralization test, imunofluorescence assay, IgM-capture enzyme linked immunosorbent assay, IgG ELISA are used for serological diagnosis of viral infections. Although most laboratories use ELISA to detect antibodies that are released after infection, it has an inherent disadvantage that it takes too long to perform. In this study, we developed a rapid diagnostic test kit to diagnose yellow fever by using monoclonal antibodies highly specific to NS1 protein obtained from yellow fever virus itself. And we performed the specificity and sensitivity of the kit among various similar viruses.

\section{MATERIALS AND METHODS}

\section{Culture of host cell and virus}

African green monkey kidney cell line (Vero, ATCC ${ }^{\circledR}$ CRL1586, Manassas, Virginia, USA) was used as host cells in this study. YF virus strain 17D was used. Dulbecco's modified Eagle's medium (DMEM, Gibco/BRL, Gaithersburg, Maryland, USA) with 2\% FBS (Gibco/BRL, 16000-044) and $0.05 \mathrm{mg} / \mathrm{ml}$ gentamycin (Gibco/BRL, 15710-064) was used as culture medium. When the Vero cells grew to $70-80 \%$ confluency, the culture was washed with PBS (pH 7.4) and then dengue, zika, chikungunya, mayaro and YF viruses were inoculated at a concentration of $0.5 \times 10^{4} \mathrm{pfu} / \mathrm{ml}$. After inoculating each virus, the flask was shaken intermittently for $1 \mathrm{hr}$ every 10 to $20 \mathrm{~min}$ to facilitate adsorption of the virus. After washing with PBS (pH 7.4), the flasks were added with DMEM containing $2 \%$ FBS and then cultured at $37^{\circ} \mathrm{C}$ in a $5 \% \mathrm{CO}_{2}$ incubator. When the cytopathic effect (CPE) of cells was observed, the culture medium was harvested and centrifuged for $10 \mathrm{~min}$ at 8,000 rpm to obtain the supernatant.

\section{Purification of YF NS1 protein}

In order to purify YF NS1 protein, we used an affinity column that was developed in a preceding study [16] in which anti-dengue NS1 polyclonal antibodies are conjugated with cyanogen bromide (CNBr) beads (GE Healthcare, Chicago, Il- linois, USA). After equilibrating the affinity column with 20 $\mathrm{mM} \mathrm{KH} \mathrm{HO}_{4}$ (pH 7.4), the acquired YF virus culture medium was loaded. After washing the unbound proteins using the same buffer, YF NS1 bound to the column was eluted with 0.1 $\mathrm{M}$ glycine ( $\mathrm{pH}$ 2.8). The $\mathrm{pH}$ level was adjusted by adding $1 \mathrm{M}$ Tris-HCl (pH 7.9) solution to 1/10 th volume of the eluted solution. The eluted YF NS1 was dialyzed with PBS (pH 7.4) and stored at $4^{\circ} \mathrm{C}$. The purified YF NS1 was dried by $1 \mu \mathrm{l}$ dripping method on nitrocellulose membrane. The nitrocellulose dot strips were blocked for $2 \mathrm{hr}$ with PBS containing 5\% skim milk, and then the antigen diluted with dilution solution (1\% BSA in PBS) was added to each strip and reacted for $30 \mathrm{~min}$. Each dot strip was washed with PBS-Tween for 1 min 5 times, and then reacted for $30 \mathrm{~min}$ at room temperature with goldconjugated protein G diluted 1:1,000 in dilution solution. Finally, it was washed with distilled water and the reaction stopped. In this study, we obtained YF NS1 $5 \mathrm{mg} / \mathrm{L}$ from the yellow fever culture media, 1 week post infection.

\section{Immunization of mouse with purified YF NS1}

Procedures to produce mAb against NS1 of YF were followed the methods described earlier $[16,17]$ with some modifications. Briefly, a 6-week SPF female mouse (Samtaco, Suwon, Korea) was immunized primarily with yellow fever NS1 $25 \mu \mathrm{g}$ in $25 \mu \mathrm{l}$ PBS mixed with Freund's Complete adjuvant (Sigma Chem Co., St. Louis, Missouri, USA) of 1:1 volume. Two weeks later, secondary immunization was carried out using incomplete adjuvant (Sigma) by the same method. Two weeks later, antibody titration was identified through indirect ELISA with blood collected from the tail. An absorbance of 1 : 1,000 diluents of 0.2 or higher seemed successful immunization, and $25 \mu \mathrm{g}$ of YF NS1 $50 \mu \mathrm{l}$ was injected into the mice's feet 5 days before cell fusion to boost the immunity.

\section{Selection of producing hybridoma monoclonal antibody and mouse ascites production}

Myeloma cells (SP2/0 cells, ATCC CRL1581) were cultured in T-75 flasks using DMEM containing 20\% FBS. The cells were fused with lymph node cells of the immunized mouse under the polyethylene glycol 1500 (PEG 1500, Sigma). Then, after reacting for $5 \mathrm{~min}$ at $37^{\circ} \mathrm{C}$, the hybridoma cells were cultured in HAT culture medium containing 20\% FBS. When the cells multiplied to $60-70 \%$ of the well plate at the bottom, the antibody titer was measured by ELISA using a plate coated with YF NS1 protein and the well supernatant in addition to 
differentiated with cross-reactions using plates coated with Zika and Dengue viruses. Wells with high antibody titers were moved into 24 well plates and cultured according to limiting dilution so that one cell per well would fit in a 96-well plate, and finally a monoclonal cell line was established.

Murine ascites were harvested after 1 week injecting $0.5 \mathrm{ml}$ of incomplete Freud's adjuvant in the abdomen of a female adult mouse with at least $5 \times 10^{7}$ hybridoma cells diluted into $0.5 \mathrm{ml}$ PBS (pH 7.4). The collected ascites was centrifuged at $4^{\circ} \mathrm{C}, 8,000 \mathrm{rpm}$ for $10 \mathrm{~min}$, and then the antibody fractions were collected with $20 \%$ to $50 \%$ ammonium sulfate precipitation. The precipitate was solved in $20 \mathrm{mM} \mathrm{KH}_{2} \mathrm{PO}_{4}$ (pH 7.4) and dialyzed (Spectrumlabs, 132724) with the same buffer. Then, it was loaded into a protein-G column equilibrated with $20 \mathrm{mM} \mathrm{KH}_{2} \mathrm{PO}_{4}$ (pH 7.4) to purify antibody by adding $1 \mathrm{M}$ Tris-HCl (pH 7.9) solution. The eluted antibodies were dialyzed with PBS (pH 7.4) and refrigerated. The purified antibodies were quantified at $280 \mathrm{~nm}$, and the protein was confirmed with $12 \%$ SDS-PAGE by Coomassie blue staining.

\section{Characterization of monoclonal antibodies}

To perform an isotype analysis, an ELISA kit was composed of a certain amount of goat antibody (Sigma) specific for mouse antibody isotypes (IgG1, IgG2a, IgG2b, IgG3, IgM, IgA) to aliquot into immune plates. After $1 \mathrm{hr}$ reaction at $37^{\circ} \mathrm{C}$ in PBS (pH 7.4), the plate was blocked with $200 \mu \mathrm{l}$ PBS containing $10 \% \mathrm{BSA}, 5 \%$ sucrose, and $0.1 \%$ Tween- 20 at $37^{\circ} \mathrm{C}$ for 1 $\mathrm{hr}$, the remaining PBS was removed and dried for $16 \mathrm{hr}$ at room temperature before use. After aliquoting the collected monoclonal culture medium into each well, it was reacted for $1 \mathrm{hr}$ at $37^{\circ} \mathrm{C}$, and then washed 3 times with PBS-T (pH 7.4). Peroxidase-conjugated goat anti-mouse IgG (Sigma, A9917) which is specific to mouse IgG is reacted at $37^{\circ} \mathrm{C}$ for $1 \mathrm{hr}$, and then substrate containing color fixing agent is used to induce colorization and identify isotypes.

The dissociation constant (Kd) for each monoclonal antibody against antigens was measured by modifying the method of Friquet et al. [18]. After reacting serially diluted antigens and antibodies at a certain concentration for $10 \mathrm{~min}$, dissociation constant was calculated using antigen-coated plates. A dissociation constant value in the range of 10-6 to 10-7 means a low coupling force between antigen-antigen, whereas a value in the range of 10-9 to 10-12 means a high coupling rate.

\section{Development of RDT to detect YF NS1}

RDT kit was composed basically of test and control lines which were divided on the nitrocellulose membrane [19]. Membranes were obtained from Advanced Microdevices (Ambala Cantt, Haryana, India) while the absorbant, sample, conjugate, and blood separation pads were obtained from Ahlstrom (Helsinki, Finland). The test line contained antibody at $1.5 \mathrm{mg} / \mathrm{ml}$ that worked as a capture site, while the control line contained goat antibody at $2.5 \mathrm{mg} / \mathrm{ml}$. Gold nanoparticle (40 $\mathrm{nm}$ in mean diameter) conjugate pads were made by soaking the antibody conjugated gold solution in glass fibers and then drying them, while the sample pads were soaked in cellulose fibers containing $0.5 \%$ polyvinyl alcohol and Tween-20 and then drying them. All pads were attached overlapping so that the sample solutions could migrate.

Monkey tissue samples were provided by Bahiafarma (based on the IRB Committee of Bahiafarma 2016-01-02), while negative blood samples were provided by the Catholic University of Korea (based on the IRB committee No. MC18SES10013). Specimens from Bahiafarma and Catholic University were all confirmed by RT-PCR. In brief, we first extracted RNA using QIAamp $^{\circledR}$ Viral RNA Mini Kit (QIAGEN, Hilden, Germany). The reagent and $10 \mu \mathrm{l}$ of RNA prep sample were then mixed using the RealStar ${ }^{\circledR}$ Yellow Fever Virus RT-PCR Kit 1.0 (Altona, Hamburg, Germany). The final mixture was loaded and run in the RT-PCR machine (CFX96 ${ }^{\mathrm{Tm}}$, Bio-Rad, Hercules, California, USA) after setting the temperature profile. The monkey tissues were crushed with a homogenizer with PBS (pH 7.4) at $1 \mathrm{ml}$ per $\mathrm{g}$ tissue, and then used. The samples received were verified 15 min after dropping $100 \mu \mathrm{l}$ onto the sample pad. The control line was checked in every test, and results without control lines were re-examined. When a band appeared on the test line, it was determined to be positive.

\section{RESULTS}

\section{YF NS1 purification and confirmation of antigenicity}

The analysis of purified YF NS1 with SDS-PAGE showed a band of approximately 45 to $50 \mathrm{kDa}$ (Fig. 1A). To confirm the antigenicity of the purified YF NS1, a dot blot assay was performed. As a result, a distinct positive reaction was observed only in the general sample in which the anti-flavivirus NS1 polyclonal antibodies were spiked, and not in normal serum (Fig. 1B). YF NS1 with confirmed purity and antigenicity was used for immunization. 
Immunization and monoclonal cell production

Immunization was performed using YF NS1 with confirmed antigenicity. The fused cells were subjected to a screening process to confirm the secretion of antibodies specifically binding

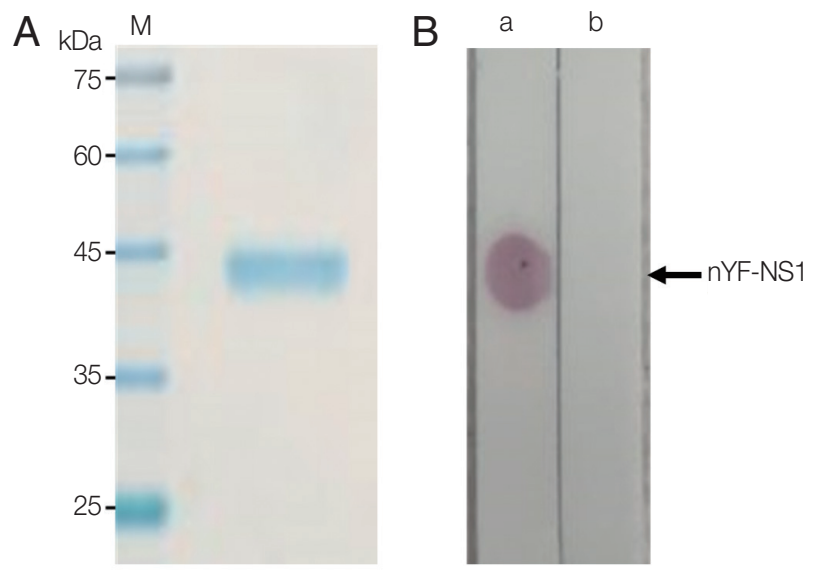

Fig. 1. Purity and antigenicity of purified yellow fever virus NS1(nYF-NS1). (A) Purified YF NS1 on SDS-PAGE gel appeared as a single band. (B) Dot blot assay showed strong positive reaction to a normal serum (a) spiked with anti-Flavivirus NS1 polyclonal antibody but not to a normal serum itself (b). to YF NS1. Screening was performed by indirect ELISA and lateral flow assay (LFA). Using indirect ELISA, 10 candidate clones were selected, in which the antibody titer was high. In addition, screening was carried out using plates coated with Zika NS1 and Dengue NS1 to confirm cross-reaction with other flaviviruses. Among the 10 highly reactive candidate clones, 7 clones were selected, except for those (1A7, 5G8, 5G9) that cross-reacted with Zika or Dengue. In order to select clones that recognize the tertiary structure, LFA was used to confirm that the candidate clones $(2 \mathrm{~B} 10,5 \mathrm{~A} 6)$, which did not show cross-reaction in indirect ELISA, showed cross-reaction between Zika and Dengue. Therefore, 3A11, 4H5, 3B7, 6C11, and $3 \mathrm{C} 4$, which are specific to yellow fever, and do not cross-react with Dengue and Zika, were selected finally. The cloning procedure was then performed twice to establish a monoclonal cell line (Fig. 2).

\section{Monoclonal antibody production and characterization}

The antibody was isolated and purified from the ascites using ammonium sulfate precipitation method and protein-G column affinity chromatography. As a result of SDS-PAGE, bands were observed near $50 \mathrm{kDa}$ and $25 \mathrm{kDa}$ (data not

A

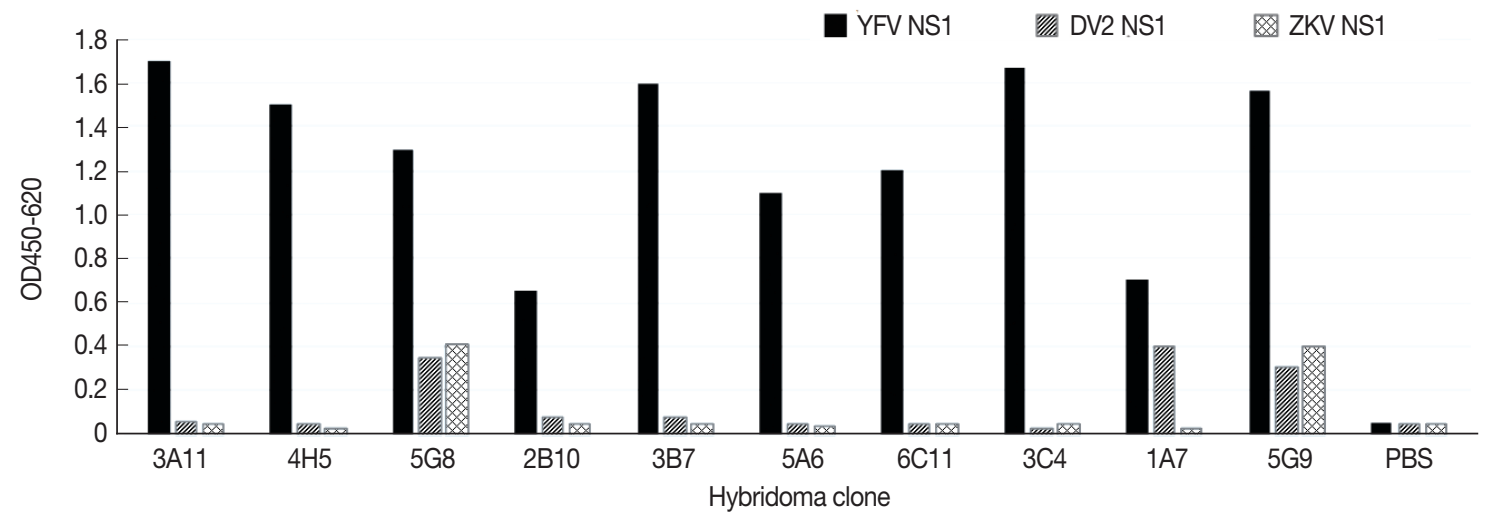

B

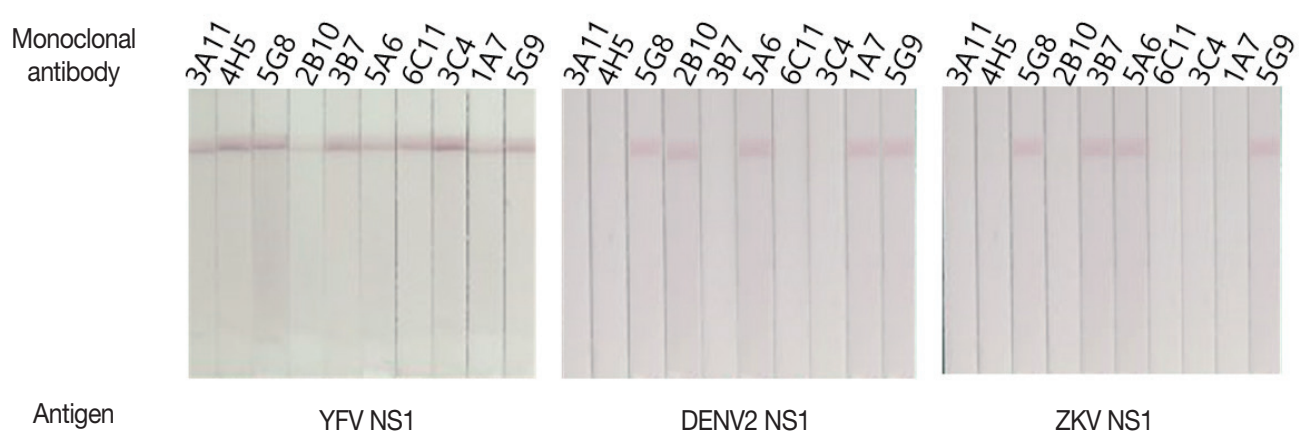

Fig. 2. Screening of YF NS1 monoclonal antibodies against flavivirus NS1 antigens. (A) Screening by indirect ELISA. (B) Screening by western blotting. 
shown), that correspond to the heavy chain and light chain in a usual antibody. Isotype and dissociation constants were determined to characterize the purified monoclonal antibodies (3A11, 3B7, 3C4, 4H5, 6C11). All monoclonal antibodies belonged in the $\mathrm{IgG}$ class and were confirmed to be isotypes IgG1 and IgG2a. The dissociation constants were determined $10^{-8}-10^{-9}$, and the antibodies with the highest affinity were 3A11 and 3B7 (Table 1).

\section{Monoclonal Antibody Pair Test and detection limit test}

$1.5 \mathrm{mg} / \mathrm{ml}$ of the 5 candidate clone antibodies (3A11, 3B7, 3C4, 4H5, 6C11) were applied on nitrocellulose membranes and gold nanoparticle conjugate solution was prepared for the pair test. Antibodies for capture and antibodies for gold nanoparticle conjugate were tested in 25 cases. Antibodies 3B7 for capture, and 3A11 for gold nanoparticle conjugate showed

Table 1. Isotype and dissociation constant of monoclonal antibody

\begin{tabular}{lcc}
\hline Hybridoma & Isotype & $\mathrm{Kd}(\mathrm{M})$ \\
\hline $3 \mathrm{~A} 11$ & $\lg \mathrm{G}_{1}$ & $7.531 \pm 0.233 \times 10^{-9}$ \\
$3 \mathrm{~B} 7$ & $\lg \mathrm{G}_{2 a}$ & $9.114 \pm 0.473 \times 10^{-9}$ \\
$3 \mathrm{C} 4$ & $\operatorname{lgG}_{1}$ & $7.781 \pm 0.403 \times 10^{-8}$ \\
$4 \mathrm{H} 5$ & $\operatorname{lgG}_{1}$ & $8.121 \pm 0.433 \times 10^{-8}$ \\
$6 \mathrm{C} 11$ & $\operatorname{lgG}_{2 a}$ & $7.888 \pm 0.307 \times 10^{-8}$ \\
\hline
\end{tabular}

the best sensitivity (Fig. 3). These 2 monoclonal antibodies were selected as the best pair to apply in developing kits for the detection of YF NS1.

Detection limit was analyzed by the recombinant protein and the virus culture were diluted by $1 / 5$, which resulted in the positive up to $0.8 \mathrm{ng} / \mathrm{ml}$ of recombinant NS1 protein and $1.6 \mathrm{pfu} / \mathrm{ml}$ of supernatant from virus culture. (Fig. 4).

\section{Specificity, sensitivity and cross reaction}

Both positive and negative monkey tissues from Bahiafarma, and negative blood samples from the Catholic University of Korea were used for clinical trials. Specificity refers to the value that a person without disease is judged to be normal through a diagnostic test. A total of 100 sera and 50 whole bloods were tested for specificity with the YF NS1 kit. No false positives were observed, the background was clean, whereas control lines were definite. Sensitivity refers to the value that a person with a disease is defined as being positive through a diagnostic test. Positive monkey tissue was used to investigate the sensitivity of the kits produced in this study.

Tests were carried out with virus cultures to determine whether cross-reaction with other epidemic Flaviviruses and Alphaviruses occurred. No cross-reaction was observed with

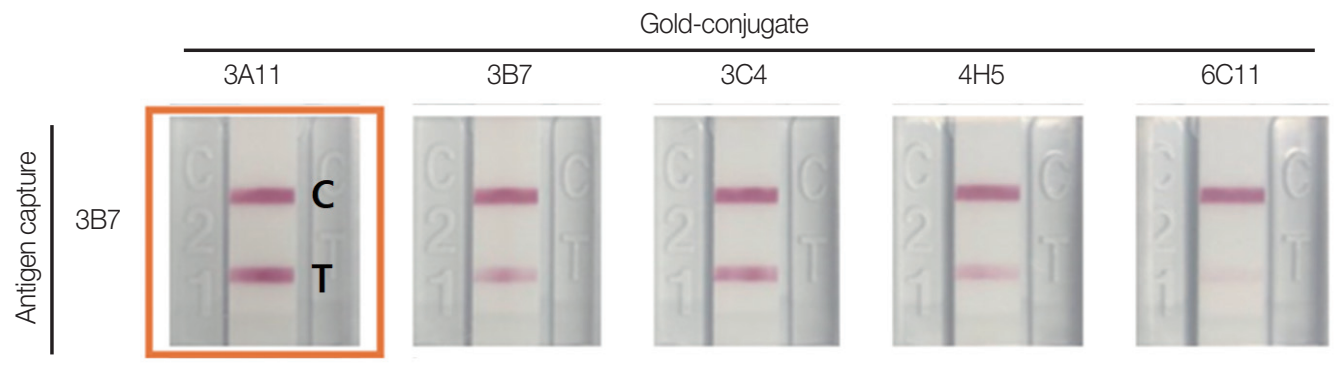

Fig. 3. Functionality of monoclonal antibodies as antigen capture or gold particle-conjugate in RDT constructs. C: control line; T: test line.

A

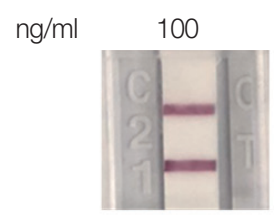

B

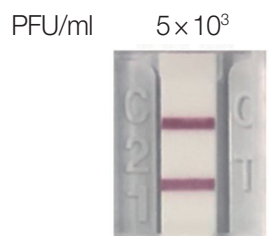

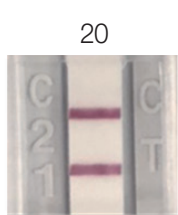

$1 \times 10^{3}$

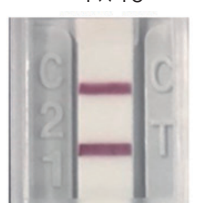

4

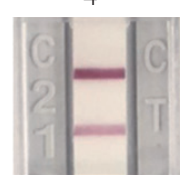

$2 \times 10^{2}$

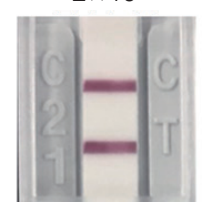

0.8

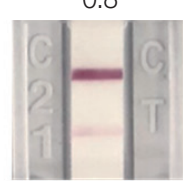

$4 \times 10$

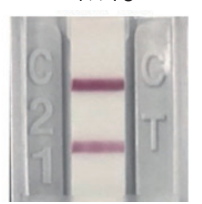

0.16

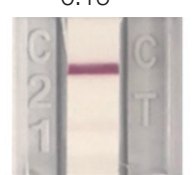

8

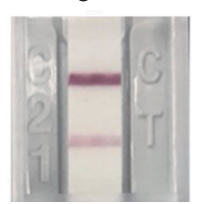

0.032

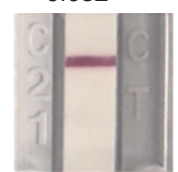

1.6

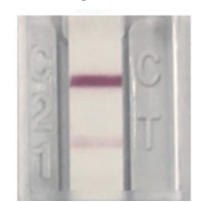

0.0064

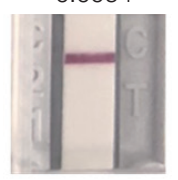

$3.2 \times 10^{-1}$

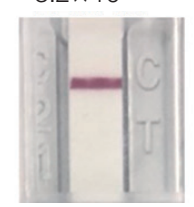

Fig. 4. Detection of RDTs for YF NS1 antigen. (A) Detection for recombinant YF NS1 protein. (B) Detection of NS1 from YF culture media. 
A
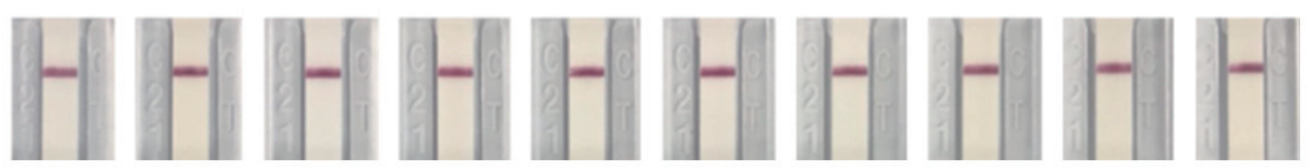

B
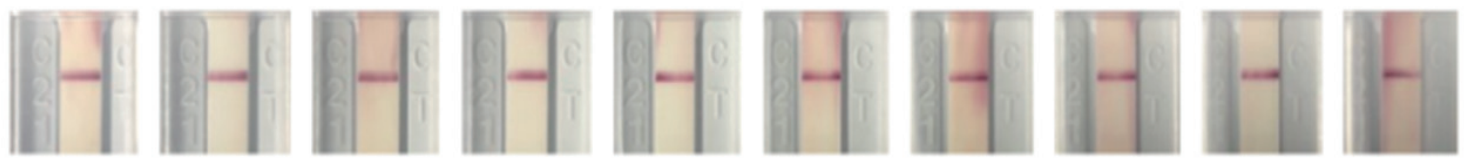

C

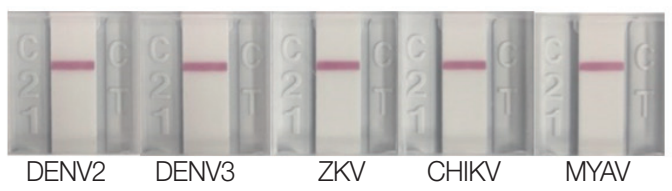

D

YF 001

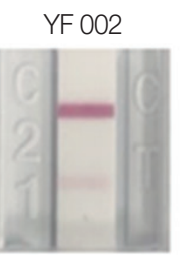

YF 003
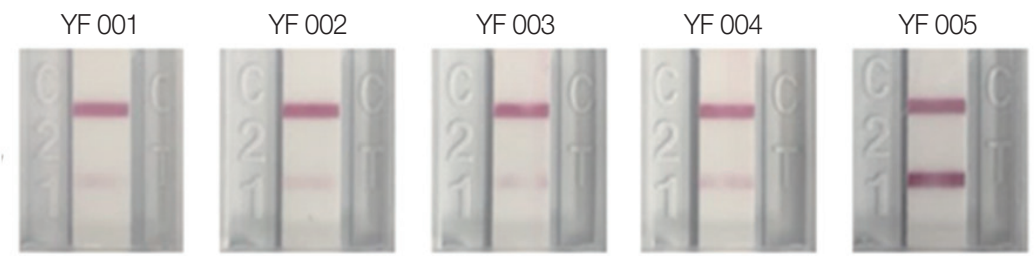

YF 006
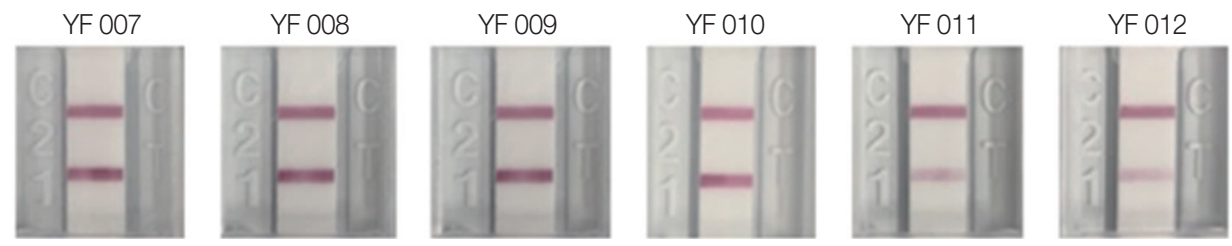

Fig. 5. Specificity of YF NS1 antigen for negative serum, negative whole blood and other arboviral culture media. (A) Reactivity to normal human sera. (B) Reactivity to human whole blood samples. (C) Reactivity to other arboviral culture media. (D) Sensitive reactions with Monkey sera infected with YF.

Dengue virus type 2 (DENV2), Dengue virus type 3 (DENV3), ZIKV, Chikungunya (CHIKV) or Mayaro virus (MAYV) (Fig. 5).

\section{DISCUSSION}

Yellow fever is an acute febrile disease caused by the yellow fever virus belonging to the Flaviviridae family, which occurs mainly in the jungle areas of Africa and South America. Although safe and effective vaccines have been in use since 1937, YF remains a major health problem in Africa and South America. Nowadays, the increase in international travelers and global warming have increased the possibility of infectious diseasecausing mosquitoes in becoming endemic, so that Korea is not safe from this risk any more.

Since YF has no effective treatment yet, it is imperative to diagnose it early and accurately. Selection of a target protein is most important in making a rapid and accurate diagnosis. Previous studies have shown that the Flaviviridae NS1 is a highly conserved protein involved in viral replication that is known to be produced a lot in the early stages of infection [20]. In addition, NS1 is known to be a good candidate for the diagnosis of viral infection since it is secreted out of infected cells at a high concentration that can be detected in the blood, and can be observed up to 9 days after the initial infection [21].

However, not much is known about the expression and secretion of YF NS1 due to the scarcity of related researches, causing us concern about its use as a marker. But as YFV belongs to same Flaviviridae family as DENV, we assumed that the similar mechanism as in the previous DENV research would exist and proceeded with the study [22].

Viruses of the Flaviviridae family have homology to each other, and NS1 has a high homology of 61\% [12] (Table 2). Taking advantage of this homology, anti-DENV polyclonal antibody developed in a previous study was attached to beads, and YF NS1 was purified by affinity chromatography. Subsequent immunization and cell fusion were carried out with this purified YF NS1.

During the screening process for monoclonal antibodies that 
Table 2. Homology of NS1 in the Flaviviridae family

\begin{tabular}{lrrrrrrrr}
\hline NS1 & DENV 1 & DENV 2 & DENV 3 & DENV 4 & JEV & WNV & ZKV & YFV \\
\hline DENV 1 & 100.0 & 73.9 & 79.8 & 69.3 & 51.4 & 51.4 & 53.7 & 41.9 \\
DENV 2 & 73.9 & 100.0 & 74.4 & 73.3 & 53.4 & 56.0 & 54.0 & 43.9 \\
DENV 3 & 79.8 & 74.4 & 100.0 & 73.9 & 51.4 & 53.7 & 55.4 & 41.9 \\
DENV 4 & 69.3 & 73.3 & 73.9 & 100.0 & 52.6 & 53.7 & 54.0 & 42.5 \\
JEV & 51.4 & 53.4 & 51.4 & 52.6 & 100 & 77.0 & 56.8 & 45.9 \\
WNV & 51.4 & 56.0 & 53.7 & 53.7 & 77.0 & 100 & 54.1 & 43.9 \\
ZKV & 53.7 & 54.0 & 55.4 & 54.0 & 56.8 & 54.1 & 100.0 & 46.7 \\
YFV & 41.9 & 43.9 & 41.9 & 42.5 & 45.9 & 43.9 & 46.7 & 100.0 \\
\hline
\end{tabular}

*Pairwise sequence comparison of the NS1 proteins from different Flaviviruses.

${ }^{* *}$ Accession no. AUW27546.1 (DENV1); CAE11558.1 (DENV2); YP_001531169.2 (DENV3); NP_740318.1 (DENV4); NP_775667.1 (JEV); YP_009164952.1 (WNV); YP_009430301.1 (ZNV); NP_776002.1 (YFV).

specifically capture YF NS1, this homology of the Flaviviridae family may in turn cause a problem in the actual screening. So screening was conducted with ELISA using not only YFV but also DENV and ZIKV NS1. However, when the native virus is tested in the field, the tertiary structure is recognized and diagnosed, but ELISA has the distinct disadvantage in that this tertiary structure breaks down due to hydrophobic binding when the antigen is coated on the plate, so we judged that screening could not be performed if the epitope of an antibody was a tertiary structure. Therefore, YF NS1 was applied to a membrane and screening was also carried out by lateral flow method.

The 2 results identified 2 candidate clones that did not cross-react in ELISA, but showed cross-reaction in the lateral flow assay. We confirmed that screening could not be performed with only ELISA if dependent solely on the antigenic determinant. Finally, we selected candidate clones that specifically target only YF NS1, without cross-reacting in both ELISA and lateral flow assay.

Finally, clones 3A11 and 3B7 were selected through antibody characterization and pair test, and the kit was prepared, and comparison tests were performed with a commercial pair from Meridian Bioscience. Detection limit was analyzed by comparing the 2 kits using recombinant protein and virus culture medium. The recombinant protein when diluted was detected better with the purchased kit, while the kit developed in this study had much better sensitivity with viral culture medium. In addition, tests with positive monkey tissues provided by Bahiafarma showed that the kit developed in this study showed high sensitivity specificity of 100\% (Table 3).

NS1 is a glycoprotein that undergoes a folding process to form a tertiary structure called glycation. Sugar chains attached to proteins may have the same effect as antigens, but there is a
Table 3. Diagnostic performance of in-house RDT compared with RT-PCR

\begin{tabular}{|c|c|c|c|}
\hline \multirow{2}{*}{$(n=124)$} & \multicolumn{2}{|c|}{ RDT } & \multirow{2}{*}{ Total } \\
\hline & Negative & Positive & \\
\hline RT-PCR & $\begin{array}{r}12 \\
0\end{array}$ & $\begin{array}{r}0 \\
112\end{array}$ & $\begin{array}{r}12 \\
112\end{array}$ \\
\hline Total & 12 & 112 & 124 \\
\hline
\end{tabular}

Sensitivity $=100 \%$, Specificity $=100 \%$.

significant difference in the glycation process and sugar structure between recombinant proteins expressed by mammalian, yeast, and insect cells. So, it is inevitable that antibodies developed by recombinant proteins have lower sensitivity compared to those developed by native antigens. We also confirmed that the diagnostic kit developed with the antibodies made with NS1 is much more sensitive.

The results of this study suggest that the rapid diagnostic kit developed in this study can be used not only for the early detection of YF virus infection, but also due to its ease in use, may contribute in eradicating YF in regions where equipment and manpower resources are poor.

\section{ACKNOWLEDGMENT}

This work was supported by the Technology development Program (S2517043) funded by the Ministry of SMEs and Startups (MSS, Korea) of 2017.

\section{CONFLICT OF INTEREST}

The authors declare that there is no conflict of interest. 


\section{REFERENCES}

1. Jentes ES, Poumerol G, Gershman MD, Hill DR, Lemarchand J, Lewis RF, Staples JE, Tomori O, Wilder-Smith A, Monath TP. The revised global yellow fever risk map and recommendations for vaccination, 2010: consensus of the Informal WHO Working Group on Geographic Risk for Yellow Fever. The Lancet Infect Dis 2011; 11: 622-632.

2. Tomlinson W, Hodgson RS. Centennial year of yellow fever eradication in New Orleans and the United States, 1905-2005. J La State Med Soc 2005; 157: 216-217.

3. Kubota RL, de Brito M, Voltolini JC. Sweeping method to scan breeding places for dengue and urban yellow fever vetors. Rev Saude Publica 2003; 37: 263-265 (in Portuguese).

4. Gubler D. The changing epidemiology of yellow fever and dengue, 1900 to 2003: full circle? Comp Immunol and Microbiol of Infect Dis 2004; 27: 319-330.

5. World Health Organization. Yellow fever (Updated March 2016) [Internet]; Available from: http://www.who.int/mediacentre/ factsheets/fs100/en/. [cited 2016 Mar 24].

6. Morlais, Severson DW. Intraspecific DNA variation in nuclear genes of mosquito Aedes aegypti. Insect Mol Biol 2003; 12: 631639.

7. Ravel S, Hervé JP, Diarrassouba S, Kone A, Cuny G. Microsatellite markers for population genetic studies in Aedes aegypti (Diptera: Culicidae) from Cote d'Ivoire: evidence for a microgeographic genetic differentiation of mosquitoes from Bouake. Acta Trop 2002; 82: 39-49.

8. Vasconcelos PF, Monath TP. Yellow Fever Remains a Potential Threat to Public Health. Vector Borne Zoonotic Dis 2016; 16: 566-567.

9. Garske T, Van Kerkhove MD, Yactayo S, Ronveaux O, Lewis RF, Staples JE, Perea W, Ferguson NM. Yellow Fever in Africa: Estimating the Burden of Disease and Impact of Mass Vaccination from Outbreak and Serological Data. PLoS Med 2014; 11: e1001638.

10. Woodall JP, Yuill TM. Why is the yellow fever outbreak in Angola a 'threat to the entire world'? Int J Infect Dis 2016; 48: 96-97.

11. Ministério da Saúde Secretaria de Vigilância em Saúde. COES Febre Amarela. INFORME - N³0/2017 [Internet]; Available from: http://portalarquivos2.saude.gov.br/images/pdf/2017/ marco/14/COES-FEBRE-AMARELA-INFORME-30.pdf.

12. Muller DA, Young PR. The flavivirus NS1 protein: Molecular and structural biology, immunology, role in pathogenesis and application as a diagnostic biomarker. Antiviral Res 2013; 98: 192208.

13. McBride WJ. Evaluation of dengue NS1 test kits for the diagnosis of dengue fever. Diagn Microbiol Infect Dis 2009; 64: 31-36.

14. Richman DD, Cleveland PH, Redfield DC, Oxman MN, Wahl GM. Rapid viral diagnosis. Infect Dis 1984; 149: 298-310.

15. Chernesky MA, Mahony JB. Detection of viral antigens, particles, and early antibodies in diagnosis. Yale J Biol Med 1984; 57: 757776.

16. Lee J, Kim HY, Chong CK, Song HO. Development and clinical evaluation of a highly accurate dengue NS1 rapid test: from the preparation of a soluble NS1 antigen to the construction of an RDT. Diagn Microbiol Infect Dis 2015; 82: 128-134.

17. Kim YH, Lee J, Kim YE, Chong CK, Pinchemel Y, Reisdörfer F, Coelho JB, Dias RF, Bae PK, Gusmão ZPM, Ahn HJ, Nam HW. Development of a rapid diagnostic test kit to detect IgG/IgM antibody against Zika virus using monoclonal antibodies to the envelope and non-structural protein 1 of the virus. Korean J Parasitol 2018; 56: 61-70.

18. Friquet B, Chaffotte AF, Djavadi-Ohaniance L, Goldberg ME. Measurements of the true affinity constant in solution of antigen-antibody complexes by enzyme-linked immunosorbent assay. J Immunol Methods 1985; 77: 305-319.

19. Chong CK, Jeong W, Kim HY, An DJ, Jeoung HY, Ryu JE, Ko AR, Kim YJ, Hong SJ, Yang Z, Nam HW. Development and clinical evaluation of a rapid serodiagnostic test for toxoplasmosis of cats using recombinant SAG1 antigen. Korean J Parasitol 2011; 49: 207-212.

20. Alcon S, Talarmin A, Debruyne M, Falconar A, Deubel V, Flamand M. Enzyme-linked immunosorbent assay specific to Dengue virus type 1 nonstructural protein NS1 reveals circulation of the antigen in the blood during the acute phase of disease in patients experiencing primary or secondary infections. J Clin Microbiol 2002; 40: 376-381.

21. Watterson D, Modhiran N, Young PR. The many faces of the flavivirus NS1 protein offer a multitude of options for inhibitor design. Antiviral Res 2016; 130: 7-18.

22. Alcalá AC, Medina F, González-Robles A, Salazar-Villatoro L, Fragoso-Soriano RJ, Vásquez C, Cervantes-Salazar M, del Angel RM, Ludert JE. The dengue virus non-structural protein 1 (NS1) is secreted efficiently from infected mosquito cells. Virology 2016; 488: 278-287. 